University of Nebraska - Lincoln

DigitalCommons@University of Nebraska - Lincoln

Management Department Faculty Publications

Management Department

2005

\title{
Implementing Affirmative Action Plans in Multinational Corporations
}

\author{
Gwendolyn Combs \\ University of Nebraska - Lincoln, gcombs2@unl.edu \\ Sucheta Nadkarni \\ University of Nebraska - Lincoln, snadkarn2@unl.edu \\ Michael W. Combs \\ University of Nebraska - Lincoln, mcombs1@unl.edu
}

Follow this and additional works at: https://digitalcommons.unl.edu/managementfacpub

Part of the Management Sciences and Quantitative Methods Commons

Combs, Gwendolyn; Nadkarni, Sucheta; and Combs, Michael W., "Implementing Affirmative Action Plans in Multinational Corporations" (2005). Management Department Faculty Publications. 50.

https://digitalcommons.unl.edu/managementfacpub/50

This Article is brought to you for free and open access by the Management Department at DigitalCommons@University of Nebraska - Lincoln. It has been accepted for inclusion in Management Department Faculty Publications by an authorized administrator of DigitalCommons@University of Nebraska - Lincoln. 


\title{
Implementing Affirmative Action Plans in Multinational Corporations
}

\author{
Gwendolyn M. Combs, Sucheta Nadkarni, and Michael W. Combs
}

\begin{abstract}
Executive Summary
Diversity is rapidly becoming an imperative business strategy in the global economy. Affirmative action is central to promoting a positive diversity climate. However, cultural, social, and legal differences around the world pose major challenges to multinational corporations (MNCs) in developing successful affirmative action plans (AAPs) at the global level. We present a model for global affirmative action plans that first identifies and examines the major environmental challenges faced by MNCs in implementing global affirmative action practices, as well as suggestions to combat these challenges. Second, the model delineates global affirmative action practices that rest on two building blocks-differentiation and integration. On the one hand, multinationals need to recognize the cultural, social, and legal differences between different countries around the world and customize affirmative action policies to each geographic context. On the other hand, they need to develop integration mechanisms to connect different affirmative action plans around the world by promoting information sharing and synergies. By effectively balancing differentiation and integration, MNCs can develop a "cosmopolitan mindset" of affirmative action that will enhance effectiveness in a global environment.
\end{abstract}

$\mathrm{W}$ ell-conceived and properly executed affirmative action plans (AAPs) maximize the positive aspects of workplace diversity. Diversity is rapidly becoming an imperative business strategy in the global economy. The National Science Board states that in 2000, in the United States alone, majority-owned foreign companies had sales of \$2.1 trillion and employed close to $5.6 \mathrm{mil}-$ lion employees. Likewise, U.S. multinational corporations (MNCs) had sales of $\$ 9.03$ trillion and employed 31.2 million employees worldwide. To successfully operate in a global environment, firms need to develop and foster diversity in their workforces. Workforce diversity is particularly important because it promotes a better understanding of diverse cultures, improves operation and product flexibility, enhances organizational creativity, facilitates better understanding of diverse and global markets, increases organization attractiveness for employees and customers and bridges insensitivities to cultural differences. Affirmative action plans aid such diversity outcomes. We assess the cultural and environmental challenges that face MNCs in developing AAPs.

Affirmative action opens opportunities for effectively using a diverse pool of individual and collective talents. Several leading multinationals, such as Microsoft Corp., Kellogg, 3M Company, Dow Chemical Co., Eastman Kodak Co., Lucent Technologies Inc., Texaco Corp. and Boeing Co., continually express their strong support for affirmative action policies. Boeing demonstrates its support through communications that stress its commitment to affirmative action as a means of creating a diverse environment consistent with business goals and market demands. Diversity, equal employment and affirmative action principles are leveraged to maintain "integrated infrastructures that promote global diversity." Despite the importance of affirmative action in MNCs, establishing affirmative action plans is challenging in the global environment because of vast differences in the legal, constitutional, social and cultural environments of different countries. We present a holistic model for developing affirma- 
tive action in MNCs by outlining the environmental challenges faced by MNCs in establishing affirmative action programs, and by identifying critical considerations in developing effective plans.

\section{The importance of affirmative action in MNCs}

Affirmative action aims at reversing past practices of discrimination. The objective is for the organizational workforce to reflect the percentage of targeted groups represented in the segments of the labor force from which it recruits workers. This process usually involves a series of results-oriented efforts in recruiting, selection, training and development, performance management and career advancement.

Affirmative action is becoming inevitable for global success. In addition to the United States, numerous countries - including Britain, Malaysia, Brazil, India, Nigeria, Canada, and South Africa - have established affirmative action directives for organizations as they seek to enhance workforce diversity globally and in specific geographical regions. Affirmative action is especially critical to MNCs because it enables them to remain competitive internationally. MNCs can benefit from effective affirmative action in several ways.

\section{Better Serving Global Markets}

Affirmative action plans can help firms serve global markets more effectively. A survey of leading U.S. multinationals among Fortune 500 companies reported that affirmative action has improved and strengthened recruitment procedures and enhanced their success in the global marketplace. The chairman of Procter \& Gamble Co. (P\&G), John E. Pepper, states "Our success as a global company is a direct result of our diverse and talented work force. Our ability to develop new consumer insights and ideas and to execute in a superior way across the world is the best possible testimony to the power of diversity any organization could ever have." Companies such as P\&G invest enormous amounts of time, talent, and resources to develop and implement highly structured affirmative action plans to foster global success. Alicia Whitaker, managing director of global human resource programs at Credit Suisse First Boston, underscores that increasingly global forces "require any organization that wants to compete effectively to be quick, sensitive, flexible, adaptable - and genuinely diverse in how it serves the marketplace. And you can't really think and act in diverse ways without having a diverse workforce, from top to bottom." Properly implemented affirmative action plans are recognized as viable tools in creating necessary workforce diversity.

\section{Developing Cosmopolitan Mindsets}

The move toward globalization has changed the skills corporate leaders say they need from their workers. Employees with "cosmopolitan mindsets" are critical to global success. Effective AAPs contribute considerably in developing cosmopolitan mindsets by increasing racial and cultural awareness through a focus on employee training and development. Employees who have a "cosmopolitan mindset" deal effectively with colleagues and customers from many different backgrounds; seek to learn about and optimize the unique contribution inherent in the culture of each individual; anticipate the impact of cultural biases on business relationships and processes; and seek to remove obstacles to equity and inclusion for each individual. Xerox Corp. ensures this type of perspective by training new employees in inclusionary principles and inculcating corporate appreciation of diverse groups as its strategic focus at all levels. According to David Matthews, director of affirmative action at KPMG Peat Marwick, the keys to global success are selecting and developing people who are not only technically competent, but are also open to various creative resources and have diverse perspectives. 
Organizations that cultivate cosmopolitan mindsets are not only able to address diverse market opportunities and the needs of diverse internal and external customers, but actively participate in creating an environment where various styles are welcomed. Successful MNCs stress this cosmopolitan mindset and seek cultural compatibility in acquiring and educating employees. For example, at Boeing, attention to cultural issues is considered first and foremost in the extensive training and orientation for internationally assigned employees and their families. Second, in facility staffing, Boeing may solicit the use of local employment agencies or hire local human resource professionals to ensure that country-specific requirements and nuances are met. Third, after acquiring an existing facility, the company often leaves existing practices intact and gradually integrates local and corporate policies as situations present themselves in the natural setting. The demonstration of such cultural competency is critical to success in a global arena.

\section{Building a Creative Workforce}

Affirmative action plans allow MNCs to incorporate "other voices" in the deliberation of organizational problems on strategic, administrative and operational levels. There is evidence that adding different perspectives can considerably improve the problem-solving abilities of employees. Other research shows that workplace diversity improves employee productivity and increases creativity and innovation because individuals from various backgrounds provide diverse ideas and strategies. Alicia Whitaker of Credit Suisse First Boston stresses that maintaining a creative workforce requires "finding and nurturing new and different ideas. More and more all the time, we need people who can contribute to a diversity of thinking styles. Recruiting and retaining people of diverse backgrounds who can share a common set of values ... and approach to business ... is a priority for today's competitive organization ... the strategic advantage becomes ... who has the best ideas? ... and the ability to execute them?"

\section{Establishing a Corporate Citizenship Image}

Failure to properly assess and manage diversity can lead to increased cases of litigation that not only raise costs, but also have a devastating effect on the company's image. Leading MNCs such as CocaCola Co. and Denny's Corp. have spent millions of dollars settling lawsuits alleging discrimination in their corporate structures or in their behavior with customers. Moreover, such lawsuits have had a negative impact on their image worldwide. Stung by the $\$ 192.5$ million class-action settlement of a racial discrimination lawsuit, Coca-Cola Co. reformulated its diversity programs to regain its image as a global citizen. Successful AAPs can considerably strengthen a firm's image among internal and external constituents (e.g., customers, shareholders, government agencies). Research suggests organizations that promote equitable recruitment, selection, and promotion of diverse individuals are perceived as responsible global corporate citizens. IBM Corp. uses affirmative action plans to monitor representation against job market availability; it uses goals and timetables to accomplish AAP objectives. Affirmative action is an important part of life at IBM and is integrated into the overall way the company conducts business. IBM's reputation around the world is evidence of its determination and proactive stance on inclusion. Additionally, such organizations receive benefits through national and international recognition and awards (e.g., Catalyst Award and Department of Labor Equal Opportunity Award).

\section{Challenges to AAPs in a multinational context}

Affirmative action is a global concept. Regardless of the country, the basic rubrics of affirmative action appear the same. Each country's affirmative action posture includes targeted groups, set goals of "fairness" and "economic parity," and some form of legal provisions for equity and inclusionary practices. In spite of these general similarities, there 
are important cross-country cultural, legal, constitutional, and historical differences that pose challenges to MNCs in developing an integrated AAP in a global context. We discuss each of these global challenges in the following paragraphs.

\section{Country Culture}

Country culture is an important global challenge because cultural differences between countries affect how people perceive, react to, and accept affirmative action policies. A country's culture reflects the beliefs, values and normative expectations and behaviors of people in that country. Three aspects of a country's culture are especially important to the development, implementation and acceptance of AAPs - individualism, pluralism and power distance.

Individualism characterizes cultures that expect each person to take care of him or herself. On the other hand, in collectivist cultures, the welfare of the group (family, racial/ethnic, kinship, language, etc.) takes precedence over individual goals and rewards. Since collectivist cultures of countries like India, Brazil, and Japan are more socially rooted, their concern for equity and justice in society could make them more accepting of AAPs than the individualistic cultures of western countries like the United States, Canada, and Britain.

Attitudes towards AAPs are a function of a culture's general normative expectations regarding collectivist and individualist orientations. Affirmative action policies have been found to be more accepted in a collectivist culture and less accepted in an individualistic culture. Additionally, even within a predominantly individualist culture, research shows that priming the independent self (individualism) and the interdependent self (collectivism) would drive the opposition or support of affirmative action in subjects. Priming the independent self undermined support for AAPs, whereas priming the interdependent self sustained AAPs.

Pluralism refers to the degree to which national culture encourages simultaneous coexistence of different ethnic groups with strong identi- ties. In a low pluralism culture such as the United States, the focus is to absorb minority groups into the dominant work culture to create uniform work norms, beliefs and values. Minority groups either completely replace their identities with those of the dominant culture, or retain weaker cultural linkages with the dominant cultural group. In highly pluralistic cultures, diverse ethnic groups with strong identities are permitted to coexist. In such cultures, seemingly contradicting thoughts and actions are tolerated, balanced, accommodated or just allowed to exist. Consequently, cultures with highly embedded pluralism, such as India, are likely to be less offended by the diversity fostered by AAPs than nonpluralistic cultures that favor a unified society.

At the same time, pluralistic cultures can also lead to negative attitudes towards AAPs because of the "in-group-out group" ideology. Due to their out-group status in a nonpluralistic culture, minority communities tend to have strong identities but weak social legitimacy. Rather than compete with minority cultures, the dominant culture aims at absorbing the minority cultures. However, in pluralistic cultures, minority groups may enjoy both strong identities and strong social legitimacy. Thus, the in-group-out-group ideology is likely to be more prominent in pluralistic countries such as India than in nonpluralistic countries such as the United States. This suggests that nonbeneficiaries in the nonpluralistic cultures such as the United States will feel less threatened by the AAPs than their counterparts in pluralistic cultures such as India.

Finally, power distance reflects the degree to which people accept and submit to authority. In high-power distance countries such as Brazil, India, Japan, and South Africa, people are afraid of authority and readily comply with authorized laws even if they disagree with the laws. On the other hand, low-power distance cultures resist authority and favor a more equal distribution of power. Thus, legal enforcements of strict affirmative action quotas are common in high-power distance countries, whereas affirmative action is driven by goals 
and timetables in low-power distance countries like the United States.

Malaysia illuminates the intersection of all three of these cultural influences on AAP implementation and perception. Collectivism and high power distance allowed the ready acceptance of a quota system for native Malays and other targeted groups. Recognizing the benefits for their own social group and those constitutionally targeted, the Chinese government leaders willingly adopted and pursued compliance. Likewise, the pluralistic nature of the Malaysian culture has had both positive and negative implications for AAPs. While working coalitions of different groups have formed to better their economic conditions, there is evidence of unfavorable perceptions and competition for AAP preferences between groups.

\section{Social Structure}

The social structure of a country involves notions of class divisions, the distribution of resources and the allocation of rewards. It also incorporates the "system" of stratifications that include such distinctions as upper and middle class, wealthy and the poor, differences in accessibility to quality education and overall levels of educational attainment, majority and minority group designations, gender and sex differences, and the ubiquitous notions of influence and power. The way a country or geographical region delineates its social structure is an important issue of equity and inclusion. An individual or group's assigned, acquired, or perceived place in the social order of a country have a considerable impact on attitudes towards affirmative action. These attitudes, in turn, have an impact on the methods and procedures appropriate for MNCs to facilitate AAP implementation and goal attainment. For instance, in South Africa the social stratification legalized through apartheid has resulted in a shortage of blacks with professional and managerial skills. Thus, MNCs in South Africa have AAPs that-in addition to hiring-emphasize internal training and development to prepare target groups for middle and upper level management roles.
Issues of in- and out-group distinctions may influence the perceptions of necessity for inclusionary practices and particularly perceptions of fairness of AAPs. Perceptions of the need for AAPs rest in recognitions of the levels and types of social stratification. For example, Indian society is based on a historical system of castes and tribes, with the priestly caste having more status, advantages, and access to different types of labor than the more disadvantaged groups of untouchables and those in remote locations. The Indian system of social norms lends itself to behaviors of ingratiation and favoritism. This history has vast implications for the types of AAP structures that will be tolerated. The social structures of South Africa and Malaysia rest on historical economic, employment, and educational restrictions for groups who constitute the majority of the population. During apartheid, native South African blacks - who are the numerical majority - became the marginalized minority in terms of social stratification and economic viability. Likewise, in Malaysia social disparity has its historical base in the lowered economic standing of native Malays in comparison with the ethnic Chinese who make up approximately $33 \%$ of the population, but control more than $70 \%$ of the country's wealth.

The United States and India offer excellent examples of the impact of social structure on the acceptance of affirmative action plans. In the case of India, an AAP structure with mandatory quotas is rooted in its hierarchical system of group status and accessibility. Perceptions of fairness center on conclusions regarding the merit of the beneficiaries of the plans and on issues of procedural justice. The attitude that AAPs compromise merit assumes that persons hired under AAPs are less qualified than nontargeted workers. Additionally, a system that is viewed to emphasize hiring based on group membership rather than individual ability or skill is perceived to violate meritocracy and the value of individual rights. While the United States does not operate under a strict caste system, it does have a history of discrimination and group oppression based on racial and ethnic lines. However, mandatory quotas are replaced by a system of goals and timetables in AAPs. 
India's historical struggle with systems of legally sanctioned oppression could lead one to conclude that Indian workers would favor more stringent approaches or quota-based AAPs. However, a recent study of Indian and United States workers by Combs and Nadkarni found both American and Indian employees preferred AAPs with less stringent numerical mandates. This is congruent with previous literature that suggests more positive attitudes overall towards AAPs when more decision choices were perceived. Conversely and contrary to existing cross-national research, Combs and Nadkarni found that Indian workers (collectivist culture) were less favorable towards AAPs than American workers (individualistic culture). And, Indian workers had less favorable attitudes towards beneficiaries of AAPs. These findings coupled with other research suggest that MNCs should not take anything for granted or rely on conventional wisdom in attempts to execute AAPs. Surprises may come in differently wrapped packages.

\section{Legal Influences}

Legal influences are indispensable in developing and implementing affirmative action plans. Legal influences reference constitutional provisions, statutes, executive orders, administrative rules and regulations, and court decisions. These laws provide the impetus for the formulation and adoption of AAPs. An examination of these laws reflects the economic, social, political, and historical conditions and events that give rise to the recognition of the need for AAPs. These laws also establish the strictures, boundaries, content, and goals of affirmative action plans. Additionally, legal influences delineate the beneficiaries of AAPs and provide insights into a nation's strategy for overcoming gender, race, ethnic, and caste discrimination and inequalities.

India, Malaysia, the United States, and Canada are excellent examples of how legal structure influences AAPs. Both India and Malaysia have instituted constitutional provisions and quotas. In India, AAPs stem from various constitutional provisions, which require quotas in government jobs and public enterprises for Scheduled Caste and Tribes and Other Backwards Classes (SC, ST and OBC, respectively). The courts have held that quotas should not be imposed so as to exclude qualified applicants of other communities; unfulfilled reservations cannot be carried to subsequent years; quotas must be less than $50 \%$ for SCs, STs, and OBCs; the determination of backwardness is not limited to caste, and that the government should adopt an economic means to prevent persons form exploiting the quota/reservation scheme. In Malaysia, severely distressed economic conditions for native Malays and Indians resulted in changes in their constitution that guaranteed preferential treatment for these groups. Quotas are permanently entrenched, in that the normal voting requirement for changing the constitution with respect to employment equity laws was superseded. Also, amendments made it illegal for affirmative action requirements to be challenged by any governing body.

In the United States, affirmative action is an outgrowth of efforts of the Congress, President, and Supreme Court to eliminate racial discrimination. Using Title VII of the Civil Rights Act of 1964, Executive Order 11246 was issued requiring affirmative action on the part of government contractors in recruiting, employment, and promotion. Subsequently, the Supreme Court assumed the major role in delineating the boundaries of affirmative action. Through various decisions, the Court has concluded that (1) raw quotas under normal circumstances violate the constitution; (2) race can be used as a plus factor in AAPs; (3) voluntary private sector AAPs are permissible provided that the measures are temporary and do not unnecessarily trammel the rights of innocent persons; and (4) diversity may be used as a justification for AAPs. Thus, public and private sector organizations are provided with the force of law to develop and implement AAPs.

In Canada, there is no formal affirmative action provision - but a host of legislative acts, court decisions, and administrative policies have emerged to improve the employment and economic status of women, aboriginals, persons with disabilities and 
visible racial minorities. The Constitution Act, with its Canadian Charter of Rights and Freedoms, Federal Contractors Program, and the Federal Employment Equity Act combined specify prohibitions against discrimination for targeted groups; legislation for employers to implement equity programs; administrative policy in the requirement of employment equity programs; and the usage of collective agreements to promote inclusion under industrial relations legislation. Because of legal and constitutional provisions of these and other countries, it is imperative for MNCs to demonstrate and act on clear understandings of legal prescriptions, restrictions, and opportunities in implementing AAPs.

\section{A model of global AAPs in MNCs}

Managing an MNC involves successfully balancing two opposing forces-differentiation and integration. On one hand, operating in a global environment requires MNCs to recognize critical differences among the cultural, social, and legal environments in different countries and adjust their strategies to each local environment. In other words, MNCs need to have distinct and customized strategies around the world. This is likely to result in country-specific and differentiated AAPs. On the other hand, overemphasizing such customization can lead to fragmentation and disintegration. To avoid this, MNCs must develop integration mechanisms by which they coordinate their local strategies with the overall goals of the organization.

Integration mechanisms allow MNCs to share valuable information across foreign units, learn from the strategic successes in different countries, and offer opportunities to exploit synergies across the strategies in different countries. Such exchange of diverse viewpoints and learning from best practices around the world can help MNCs move their affirmative action efforts from the domestic level to a global level. Establishing such global affirmative action practices can help a firm to better serve global markets, develop a creative global work- force, and build a global corporate citizenship reputation. Jain, Sloane, and Horowitz, in their examination of international employment equity and affirmative action, conclude that while basic practices may be desired and needed, multinationals should consider the unique features of the local context in the design and implementation of AAPs.

Some MNCs find a "structured decentralized" approach to be helpful. A central governing and oversight body or council outlines plan requirements and overall organization expectations, with individual facilities developing AAP strategies tailored to their specific needs and country process. For example, in the Asia-Pacific operations of one major global pharmaceutical company, a host country local (within the scope of target groups) supplies candidates for open positions based on a very selective process to ensure local goodwill, image, and positive relations with the Kieritsu and local community and political leaders. Home-country executives then make the final selection, ensuring compliance with legal requirements of both countries and corporate expectations. We propose that developing effective AAPs in a multinational environment requires MNCs to effectively balance the differentiation and integration of their AAPs around the world. In what follows, we explain our suggestions for achieving differentiation and integration of AAPs in a global environment.

\section{Differentiation}

We suggest that firms need to customize their AAPs to the local environment by selecting the appropriate AAP structure, adopting appropriate AAP requirement policies, and defining clearly the target groups of AAPs.

AAP structure - In developing AAPs, it is necessary for multinationals to determine their approach to affirmative action planning. Kravitz and colleagues describe two primary types of AAP structures: opportunity enhancement and preferential treatment. Opportunity enhancement plans 
involve efforts to increase job applications from qualified target-group members, or to hire from target groups when their qualifications are equal to those of nontarget group members. Opportunity enhancement AAP structures do not require rigid numerical goals or quotas. In such AAPs, organizations proactively seek and promote racial/ ethnic minorities and women under more fluid guidelines and flexible operational procedures. On the other hand, preferential treatment plans employ more rigid structures that strictly adhere to hiring persons due to their race, ethnicity, gender, caste or class background and may result in the hiring of less qualified minorities and women over more qualified nonminorities and men. For MNCs, cultural differences in the varying geographical regions in which their facilities operate can make, deciding on an AAP approach, a very critical step in the effective implementation of AAPs.

An organization's determination of an AAP structure is contingent on its appropriateness to the local country's legal as well as social environment. For example, South Africa and India have important legal distinctions for affirmative action implementation. The prescribed structure of AAPs in South Africa involves a system of goals and timetables with specific identification of problem areas, following an opportunity enhancement AAP structure. The implementation plans for affirmative action have primarily been clarified and delineated through the Employment Equity Act and policy guidelines from the Black Management Forum, the National African Federated Chamber of Commerce and the Employment Conditions Commission. South Africa has resisted a legislative interventionist approach with merit, tokenism, and reverse discrimination being reasons for not legislating affirmative action. The implementation of affirmative action in India is quite different, following more of a preferential treatment structure. Affirmative action policy in India is a classification of strict quotas and reservations. Specific numerical requirements are maintained for targeted groups considered to be economically oppressed, and to have low access to employment and education. Quotas that total approximately $50 \%$ for these groups are codified in India's Constitution.

The success of an AAP structure is also contingent on adherence to the cultural and social environments of a country. This is because reactions to specific structures of AAPs are closely tied to the degree of individualism and pluralism, and the "system of social stratification" in each country. For example, preferential treatment structure AAPs invoke negative reactions in Canada, the United States and Britain because such plans are perceived to compromise individual merit and promote the hiring of less qualified members of targeted groups. Target groups in these countries have weak ties to the dominant group and enjoy weak social legitimacy. Additionally, the use of quotas and strict numerical goals in preferential treatment AAPs is perceived to violate procedural justice and result in unfair treatment of persons who are nontargeted group members, but possess higher qualifications. On the other hand, opportunity enhancement AAPs are perceived as less rigid in conceptualization and more flexible in operation.

Preferential treatment structures also invoke negative reactions in India and Brazil due to fairness issues. However, the notion of fairness is different from that in the United States. A major source of discontent over preferential treatment AAPs in India is the "creamery effect" that is tied to the socio-economic status of the beneficiaries. AAPs have been criticized in India on grounds that they mainly target individuals with high socio-economic status who do not need aid, but enjoy the rewards of AAPs. In Brazil, the high level of miscegenation or race mixing is viewed by some to be the source of anthropological distinction and pride. The inability to technically and intellectually distinguish black from white, coupled with a census process that incorporates over 100 different racial designations, causes great opposition to a system of racial quotas afforded to Brazilian blacks. 
To mitigate negative reactions to AAPs, especially preferential treatment AAPs, firms need to develop effective communication programs that inform employees of the benefits of the plans, to provide forums that foster interactions between target and nontarget groups and to allow employees to provide feedback on their specific concerns. Organizations such as IBM, Boeing, Xerox Corp., and Motorola Inc. are very vocal and transparent in their efforts towards inclusionary practices. Their policy statements and diversity initiatives clearly embrace enhanced recruitment, selection and development of groups targeted by affirmative action. Specifically, Xerox in support of its goal to leverage differences as a competitive advantage, pushes for a balanced workforce reflecting equitable representation in all areas of the company, provides direct senior management and employee interactions through employee roundtables, and stresses training, development, and succession planning to facilitate upward mobility and diverse representation at all management levels. Such AAP communication, feedback, and training programs need to be tailored to suit the legal and social environment of each country.

AAP policy requirements - Another major issue that differentiates AAPs is whether such policies are mandatory or voluntary. This choice is also contingent on the legal requirements in each country. For example, in the United States, affirmative action plans are not constitutionally mandated. AAPs have the force of law from Presidential Executive Orders for government contractors (public and private) and as a direct remedy for demonstrated discrimination through judicial decisions and conciliation agreements. Consequently, the adoption of affirmative action programs is voluntary for the vast majority of private sector organizations. AAP goals and timetables must be based on labor force characteristics of the relevant recruitment areas from which workers are actually or expected to be hired. Although organizations have considerable flexibility in determining specific AAP activities, precedents from court decisions and directives from regulatory agencies must be followed to insure the legality of the plans.

Likewise, Britain and South Africa have settled on voluntary measures to ensure increased employment opportunities for targeted groups. Constitutional and legislative actions have not made AAPs mandatory. However, each country has specific reporting and monitoring provisions and guidelines for public and private sector employers. Additionally, there are oversight bodies that have the authority to conduct onsite reviews, make program recommendations, and initiate sanctions for noncompliance with guidelines.

In India, special commissions that are mandated in the country's constitution conduct the clarifying discussions that give legal impetus to affirmative action. The Mandal Commission issued a report in 1980 that identified the total reservations for Scheduled Tribes and Scheduled Caste, and Other Backwards Classes as $22.5 \%$ and $27 \%$, respectively. The Mandal Report suggested that at that time there were approximately 3,784 castes designated as backward and required a reservation or quota for $49.5 \%$ of all government jobs and educational seats. However, such quotas do not apply to a vast majority of private sector firms.

Organizations should articulate specific justifications for the implementation of AAPs. Kravitz and colleagues identify two justifications. The "compensation" justification suggests that affirmative action makes up for past discrimination and levels the playing field for targeted groups. The "instrumental" justification suggests that affirmative action enhances organizational effectiveness through increased diversity. MNCs such as IBM, Xerox and Motorola use one or both of these justifications in communicating their reasons for adopting an AAP. Laws, customs, and requirements of different countries and regions are adhered to in communicating affirmative action and nondiscrimination policies and procedures. 
AAP target groups - Another critical aspect in developing AAPs is the definition of target groups. MNCs need to clearly define the beneficiaries of affirmative action plans by taking into account the social history and legal directives of the country. For example, affirmative action in the United States (in pure terms) is predicated on the elimination of employment imbalances for specific racial, ethnic, and gender groups that have been historically discriminated against (e.g., African American, Hispanic Americans, Asian Americans, Native Americans and women). Comparison of the composition of the organization's workforce with the relevant labor market dictates which specific racial/ethnic or gender groups will constitute a goal. In Canada, prohibitions against discrimination and legislative enactments seek to protect rights and increase employment alternatives for four specifically designated groups. Governmental agencies and private employers face strict reporting and program requirements for women, visible racial minorities, aboriginals, and persons with disabilities. India's affirmative action is referred to as compensatory discrimination among castes for subjection to past discrimination and oppression. These groups are Scheduled Castes (SC) who were previously considered the "untouchables," Scheduled Tribes (ST) representing Indians living in remote and very rural areas, and Other Backwards Classes (OBC) representing a catch-all group of other segments of the population that experienced historical exclusion. Attention to these groups is codified in the constitution of the country for what are termed as the socially and economically depressed classes. Unlike the United States, women are not a part of the targeted groups in India. Thus, firms need to consider the social and cultural histories of countries before defining the target groups of AAPs.

Other countries may have different designations of groups targeted for affirmative action efforts. In South Africa and Malaysia, AAPs cover black South Africans and native Malays, respectively - who are the numerical population majority but have been historically relegated to "minority status." Race rather than gender differences are prominent. Similar to the United States, Britain and France stress both racial and gender equity.

\section{Integration}

To globally integrate AAPs, multinationals need to develop comprehensive programs that allow information sharing, exploitation of synergies, and dissemination of performance feedback from different countries. In the following paragraphs, we discuss the important elements for AAP integration.

Top management involvement - Top management involvement is critical to the success of AAPs. Without significant top management involvement, the strategies become superficial, restricted, and fragmented. For example, Xerox has a history of continuity and top management involvement in AAP implementation. When the company initiated affirmative action efforts in the United States in the 1970s, the chairman played a pivotal role in supporting, coordinating, and ensuring success. Xerox aggressively pursued an affirmative action posture that stressed management accountability through both positive (bonuses and promotions) and negative (warnings and demotions) reinforcements. Significant top management involvement and interest mitigated much resistance. The chairman of Michcon, a wholly owned subsidiary of GTE Energy, links affirmative action initiatives upfront to strategic business goals and objectives. The company vision and values statement was changed to reflect the initiatives, and a videotape of the chairman expressing why affirmative action is important at Michcon was shown to all employees. This action was critical to the success of AAPs at Michcon, by properly positioning affirmative action as an organizational initiative.

MNCs using top-level management involvement as a seed to AAP implementation must be mindful of the potential impact of cultural differences on the perception and success of this approach. For in- 
stance, in high-power distance cultures, direct and forceful top-level management involvement could work well to ensure basic compliance. However, obtaining information on how employees really feel and ensuring genuine embracement of inclusionary practices may require subtler and less direct management involvement on an operational level. Upward and downward communication may need to be tailored to fit the cultural norms of specific geographical regions. Top management must become versed and help others to recognize that "one size may not fit all" in implementing AAPs. At Boeing, communication and subsequent AAP policy decisions reflect an interactive process between corporate executives and global managers. While overall vision and expectations (e.g., hiring, promotion, and pay policies) are articulated, executives allow and support input from global managers that reflect local cultures and customs. IBM has established target group executive task forces that are led by top company executives who comprise a worldwide management council. Task force goals are to "ensure the removal of barriers that would keep employees of these groups from feeling welcomed, valued and more productive ... and, to develop recommendations that would help recruit and retain the best talent represented by these groups."

Liaison units - Liaison units play a critical role in coordinating AAP activities nationally as well as internationally. For example, some companies either establish a new position or assign responsibilities to an existing position allowing for an " $A A P$ Coordinator, Manager or Director" who oversees the formulation and implementation of AAPs in each unit. (Depending upon the organization, the definition of "unit" can vary in size or functional responsibilities.) This is usually a high-level position with access to top decision makers. The main function of the AAP coordinator is monitoring programs and compliance issues, as well as fostering cross-cultural learning and operational efficiency at the global level. In some organizations the liaison position is specifically designed for affirmative action, whereas in other organizations the director of diversity or human resources vice president has the AAP responsibilities. Whether the position of "AAP coordinator" is distinct or a part of diversity initiative, there is a close relationship between the AAP function and top management. The AAP coordinator position is the link for differentiation and integration of affirmative action policies. For example, at Xerox the affirmative action plan is referred to as the Balanced Work Force Initiative; it works in tandem with the company's diversity programs.

Success of the liaison role requires a consultative and participative process rather than an authoritarian approach. Xerox has a set of core values related to fair treatment that must be adhered to by all facilities. However, facilities are given latitude to accomplish the goals of the Balanced Work Force Initiative within the constraints and opportunities faced in the country in which the facility operates. Additionally, the liaison can serve an informational role by keeping target group networks abreast of organizational demographics and assisting in the presentation of issues to organizational executives.

Cross-country minority networks - Minority networks are becoming an increasingly popular tool to support AAPs in multinational corporations. Minority networks provide a forum for minority target groups to exchange strategic information and explore nontraditional ways to recruit, mentor, and promote minority workers within the organization. Network members develop and participate in activities that support AAP efforts. These activities include seminars, organizing college recruiting, career/development opportunities, and mentoring. These types of activities not only benefit minority groups by allowing employees from similar backgrounds and cultures to share experiences and learn from each other, but also mitigate the sometimes-unfavorable majority group perceptions of AAP beneficiaries. When Xerox encouraged the development of minority caucuses in 
the early 1970s to provide advice and help to minority workers such as African Americans, Asians, Hispanics, and women, it was considered radical. However, with the growing global success of Xerox as a multicultural MNC, other companies are beginning to recognize the benefits of such networks. Some MNCs are taking the concept of minority networks to an international level. For example, General Electric Co. and Microsoft Corp. have developed separate forums for different AAP target groups (such as African American forums, Hispanic forums, and women's network) around the world. Such international minority networks further what GE calls "horizontal learning" across the different network groups through diverse cultural and ethnic exchanges among these networks around the world. Such horizontal learning is especially critical to the success of an integrated AAP program.

Such networks can benefit organizations globally by helping the company connect with different markets. Motorola's Asian Business Council has helped the company promote products at events such as the U.S.-China Economic Development Forum. Likewise, African American and women's networks might be used to connect with international markets with high black populations or those that have concerns about the empowerment of women. Avon Products, Inc. uses its networks to bridge issues for management and associates, and to inform the organization of significant workplace and marketplace issues. Using target group networks in these ways requires extensive preparation and training on the cultural, social, political, and legal expectations of different countries.

Global AAP practices - Developing global AAP practices offers opportunities to exploit synergies across the different AAPs. Firms could establish a common structure of AAP practices and support programs at the global level and then customize the content to the needs of each country. Successful MNCs such as GE, Microsoft and Mo- torola have developed effective global diversity training programs that provide a common platform around the world, but at the same time provide the flexibility to adapt to specific needs of each country. MNCs can strengthen such global affirmative action practices through forums such as seminars, conferences, and meetings at the regional level (e.g., North America, Indian subcontinent, West Europe) to share best business practices and establish some commonality across regions that are culturally, socially, and geographically close. These cross-country forums, formal and informal exchange networks, and information sharing sessions can help multinationals define their specific AAP focus and identify appropriate methods and mechanisms to sustain inclusionary efforts. Through such regional integration, MNCs can gain economies of scale and procedural efficiency in addressing strategic, administrative and operational issues and problems relating to AAPs. For example, many AAPs include a provision for increasing the number of minority/ women owned contractors/suppliers. In collectivist cultures where patronage and favoritism exist, such practices may be well tolerated - while in individualistic cultures the notion of such set-asides may be sharply challenged. Therefore, the examination of regional best practices to create global synergy may reveal program outcomes that are bounded by the specifics of law, culture, and social structure.

Global AAP evaluations - The final component of an AAP is performance monitoring. Research suggests that numerical goal setting is a necessary component. An example of numerical goal setting is relating a considerable portion of senior managers' performance review to AAP progress. For example, $20 \%$ of Xerox's senior managers' (vice presidents, departmental, and regional managers) performance reviews cover their performance in hiring, training, and promoting target-group workers. What is critical for an MNC is to develop 
specific numerical goals that allow cross-country comparisons of AAP performance of top managers. Another form of AAP evaluations is developing formal databases of AAP goals and timetables and the actual performance of units in each country. Firms then track the extent to which the separate units complied with the goals and timetables set for their unit. Such databases also need to be standardized to some extent, so that the performance of units from different countries can be compared. While outcome assessment is critical, to reap the best benefit MNCs should seek flexible accountability approaches with multiple metrics to reflect cultural norms of different countries and geographical regions.

AAP performance cannot be measured solely by increases in the numbers of targeted group workers hired in the company. Employee surveys are a powerful tool to evaluate the extent to which beneficiaries as well as nonbeneficiaries of AAPs are satisfied with the programs. Several successful MNCs, such as Motorola, conduct yearly or 6-month surveys to measure employees' perceptions of their work climate-including respect, fairness, growth opportunities, and discriminatory experiences. IBM conducts "global pulse surveys" that tap into employee perceptions about operational processes and their treatment in the organization. Other indicators of AAP success are the number and type of employee complaints relating to discrimination and inequality. MNCs such as Michcon and Motorola are in the process of implementing these AAP evaluation practices at the global level. Determining success will necessitate knowledge of the legal and constitutional hiring prescriptions and/or quotas and general methods for data gathering for a country. Also, a clear understanding of the static or dynamic designation of target populations and the general level of acceptance for specific procedures will assist evaluation processes globally and for specific geographical regions. Developing global affirmative action evaluation databases, publicizing best AAP practices around the world, and recognizing best affirmative action units around the world are a part of monitoring affirmative action practices on a global level.

\section{Conclusion}

Maintaining and managing a diverse workforce and satisfying diverse constituents require MNCs to integrate effectively differing affirmative action requirements and expectations. Success rests on the ability of multinationals to effectively navigate the cultural, social, and legal structures of varying countries that constitute a global mindset for AAP development and implementation. Within the context of these constraints, MNCs must first differentiate their affirmative action strategies in terms of structure, policy requirements as a function of constitutionality or judicial and regulatory review, and goals and objectives pertinent to the specific facility and labor market situation. Second, MNCs must attempt to integrate across cultural divides to facilitate information-sharing that leads to horizontal learning, spark the energy and enthusiasm to capitalize on best practices, obtain cross-cultural synergies, and appropriately assess and evaluate AAP outcomes. This mission-if accomplished-will take multinational corporations to a level of affirmative action plan innovation "where no person has gone before." 


\section{Selected bibliography}

For further reading on general and international affirmative action, see H. C. Jain, P. J. Sloane, and F. M. Horwitz, Employment Equity and Affirmative Action (New York, NY: M.E. Sharpe, 2003); G. M. Combs and S. Nadkarni, "The Tale of Two Cultures: Attitudes towards Affirmative Action in India and the United States," Journal of World Business, in press; D. A. Kravitz, D. A. Harrison, M. E. Turner, E. L. Levine, W. Chaves, M. T. Brannick, D. I. Denning, C. J. Russell, and M. A. Conard, "Affirmative Action: A Review of Psychological and Behavioral Research," a monograph published in 1995 by the Society for Industrial and Organizational Psychology, Inc. P.O. Box 87, Bowling Green, $\mathrm{OH}$ 43402-0087; D. A. Kravitz and S. L. Klineberg, "Affirmative Action Attitudes: Effects of Respondent Ethnicity, AAP Strength, and Anticipated Impacts," Academy of Management Proceedings, 2002; V.
Pucik, N. Tichy, and C. Barrett, Globalization and Human Resource Management (New York, NY: Wiley, 1994); and K. Ozawa, M. Crosby, and S. Crosby, "Individualism and Resistance to Affirmative Action: A Comparison of Japanese and American Samples," Journal of Applied Social Psychology, 1996, 26, 1138-1153.

For additional reading on culture and social structures, see G. Hofstede and M. F. Peterson, "Culture: National Values and Organizational Practices," in N. M. Ashkanasy, C. P. M. Wilderon, and M. F. Peterson (Eds.), Handbook of Organizational Culture and Climate (Thousand Oaks, CA: Sage, 2000, 401-415); H. C. Triandis, Individualism \& Collectivism (Boulder, CO: Westview Press, 1995); R. C. Smith and R. Seltzer, Race, Class \& Culture: A Study in Afro-American Mass Opinion (Albany, NY: State University of New York Press, 1992).

Gwendolyn M. Combs is an assistant professor of management at the University of Nebraska-Lincoln, Lincoln, Nebraska, where she teaches in the areas of organizational behavior and human resource management. Combs received her Ph.D. from the University of Nebraska-Lincoln. Her research focus is the effective acquisition and integration of employees in organizations, which includes the areas of recruitment and selection, employee development, positive organizational behavior, affirmative action, and diversity management and leadership in organizations. Combs consults in the areas of human resource planning, employee relations, recruitment and selection, affirmative action program planning, and diversity program development and training. She has published in The Journal of World Business, Journal of Leadership Studies, Human Resource Management Review, and Howard Law Journal. Tel. 402 472-6061; fax 402 472-5855; e-mail gcombs2@unl.edu 
Sucheta Nadkarni is an assistant professor in the department of management at the University of Nebraska-Lincoln. She holds a Ph.D. in business from the University of Kansas. Her articles have been published in journals such as Academy of Management Learning and Education Journal, Decision Support Systems, European Journal of Operations Research, Journal of World Business, Organizational Research Methods, and MIS Quarterly. Her research interests include the role of managerial cognition in strategic management and international business, causal mapping, and affirmative action and diversity issues in international business. Tel 402 472-8399; email snadkarn2@unl.edu

Michael W. Combs is a professor of political science at the University of Nebraska-Lincoln, Lincoln, Nebraska, where he teaches in the areas of African American Politics, American Politics and Civil Liberties and Constitutional Law. Professor Combs received his Ph.D. in Political Science from Washington University at St. Louis. His articles have been published in journals such as The American Political Science Journal, The Western Political Quarterly, The Urban Affairs Quarterly, and various law reviews. His research interests include the saliency of racism in policy making, the nexus of culture, racism and law, and affirmative action. Tel 402 472-3231; e-mail mcombs1@unl.edu 